\title{
Control with Sliding Mode of a Five-Phase Series-Connected Two- asynchronous Motor Drive
}

\author{
Omar zouaid ${ }^{1}$, Lazhari nezli ${ }^{2}$ \\ ${ }^{1}$ Polytechnic National School of Algiers, ALGERIA \\ ${ }^{2}$ Laboratory of control and process (LCP), Polytechnic National School of Algiers, ALGERIA \\ o_zomardj125@yahoo.fr
}

\begin{abstract}
$\overline{\text { Abstract - In this paper, we study sliding mode control of series-connected five-phase two }}$ asynchronous machines supplied with a three levels inverter. After presentation of multiphase machines, we worked out the mathematical model of five phase asynchronous machine supplied with voltage inverter. Application of Park transformation reduces considerably the mathematical model of machine. After, we applied vector control and sliding mode control to the five-phase induction machine. After that, we study a multi-machine system, which comport five-phase two asynchronous machines supplied with a single voltage inverter.

In the last, we had the sliding mode control of series-connected five-phase two asynchronous machines. Simulations are presented to show the effectiveness of the control strategy. We observe that an appropriate transposition of phase's order permits an independent control of two machines.
\end{abstract}

Keywords: Five-phase, asynchronous machine, multi-machine systems, phase's transposition, sliding mode control

Received: 01/06/2018 - Accepted: 28/06/2018

\section{Introduction}

Ever since the inception of the first five- phase variable speed drive in 1969 [1], five-phase machines have been considered as a viable alternative to threephase machines. This especially holds true for highpower and safety-critical variable speed applications, where a five-phase drive can be realized using inverters with smaller rating per leg while enabling fail-safe operation in redundancy mode $[2,3]$.

A vector control scheme for a five-phase machine is in its basic form, regardless of the machine type, identical to the corresponding vector control scheme for a threephase machine $[4,5]$. However, since vector control of an ac machine requires only two axis currents for decoupled flux and torque control, higher torque density can be achieved in a five-phase machine by utilizing the remaining two degrees of freedom. The injection of the third stator current harmonic enables utilization of the third spatial harmonic of the field for torque production, in addition to the fundamental harmonic of the field $[2,3]$.

A rather different use of these additional degrees of freedom was proposed in [5]. On the basis of considerations related to the machine's rotating field, it was suggested to connect two five-phase machines in series and supply them from a single five-phase source. By introducing an appropriate phase transposition in this series connection, it was reasoned that the two machines could be controlled completely independently, using basic vector control schemes, although they are supplied from the common five-phase source. The major advantage of such a two-motor drive system is the reduction OP the number of required inverter legs, when compared to an equivalent two-motor three-phase drive system (from six to five). This translates into increased reliability, due to a smaller number of components.

On the basis of this novel $\mathrm{d}-\mathrm{q}$ axis model of the seriesconnected two-motor drive system, an indirect rotor flux oriented control scheme is designed.

A detailed simulation study is finally undertaken. The complete drive system, including the hysteresis current controllers and the voltage source inverter (VSI), is simulated for a number of transients. It is shown that completely decoupled flux and torque control results not only for each of the two machines, but for one machine with respect to the other as well. The correctness of the developed models and the vector control scheme are verified in this way

\section{Description of the drive}

The drive consists of two five-phase machines, which can be either induction or synchronous (permanent magnet or synchronous reluctance) and which can be freely mixed within the system. It is here assumed that the machines in question are both induction motors, 
without any loss of generality. Five-phase stator windings of the two machines are connected in series, with an appropriate phase transposition, as illustrated in Fig. 1. Phase transposition in the series connection is a necessary prerequisite for independent vector control of the two control. Inverter phase sequence is denoted in Fig. 1 with capital letters A,B,C,D,E, while the phase sequence of the two machines, respecting the spatial distribution of the windings, is identified with lower case letters a,b,c,d,e. Spatial displacement between any two consecutive phases in the machines equals $\alpha=2 \pi / 5$.

According to the connection diagram of Fig. 1, inverter phase-to-neutral voltages and the correlation between inverter output currents and machine phase currents are given with

$$
\begin{gathered}
v_{A}=v_{a s 1}+v_{a s 2} \\
v_{B}=v_{b s 1}+v_{c s 2} \\
v_{C}=v_{c s 1}+v_{e s 2} \\
v_{D}=v_{d s 1}+v_{b s 2} \\
v_{E}=v_{e s 1}+v_{d s 2} \\
i_{A}=i_{a s 1}=i_{a s 2} \\
i_{B}=i_{b s 1}=i_{c s 2} \\
i_{C}=i_{c s 1}=i_{e s 2} \\
i_{D}=i_{d s 1}=i_{b s 2} \\
i_{E}=i_{e s 1}=i_{d s 2}
\end{gathered}
$$

It is assumed for modeling purposes that all the standard assumptions of the general theory of electrical machines apply [9], including the one related to sinusoidal distribution of the resulting field in the machine. Rotor windings are initially taken as five-phase as well, for the sake of generality.

\section{Drive Modelling}

\section{III.1. Phase-Variable Model}

Two machines of Fig. 1 are assumed to be of different parameters and ratings, for the sake of generality. The electrical subsystem's model of the drive in Fig. 1 is of the $15^{\text {th }}$ order and it can be represented in matrix form (underlined quantities) with

$$
\underline{v}=\underline{R} \underline{i}+\frac{d(\underline{L} \underline{i})}{d t}
$$

Where machines. Its purpose is to make flux/torqueproducing currents of one machine non flux/torqueproducing currents in the second machine, and vice versa
[5]. The two-motor drive is supplied from a single fivephase VSI, which is current controlled. Current control is exercised upon phase currents in the stationary reference frame, using either hysteresis or ramp-comparison current

$$
\underline{v}=\left[\begin{array}{l}
\underline{v}^{I N V} \\
\underline{0} \\
\underline{0}
\end{array}\right] \quad \underline{i}=\left[\begin{array}{l}
\underline{i}^{I N V} \\
\underline{i}_{r 1} \\
\underline{i}_{r 2}
\end{array}\right]
$$

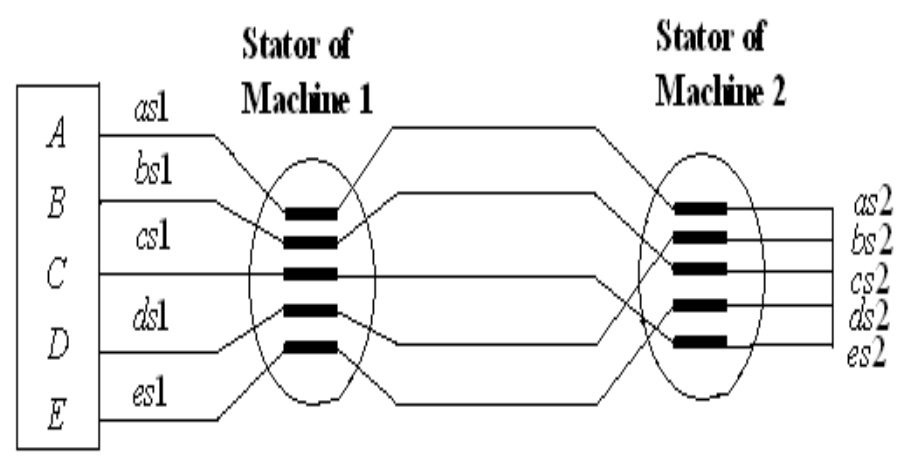

Figure1. Five-phase two-motor drive with series connection of phase windings and an appropriate phase transposition.

$$
\underline{v}^{I N V}=\left[\begin{array}{lllll}
v_{A} & v_{B} & v_{C} & v_{D} & v_{E}
\end{array}\right]^{T}
$$

$$
\begin{gathered}
\underline{i}^{I N V}=\left[\begin{array}{lllll}
i_{A} & i_{B} & i_{C} & i_{D} & i_{E}
\end{array}\right]^{T} \\
\underline{R}=\left[\begin{array}{llll}
\underline{R}_{s 1}+\underline{R}_{s 2} & & \\
& \underline{R}_{r 1} & \\
& & \underline{R}_{r 2}
\end{array}\right]
\end{gathered}
$$

$$
\underline{L}=\left[\begin{array}{ccc}
\underline{L}_{s 1}+\underline{L}_{s 2} & \underline{L}_{s r 1} & \underline{L}_{s r 2} \\
\underline{L}_{r s 1} & \underline{L}_{r 1} & \underline{0} \\
\underline{L}_{r s 1}{ }^{\prime} & \underline{0} & \underline{L}_{r 2}
\end{array}\right]
$$

Sub-matrices of the inductance matrix identified with the prime symbol are those whose form has been altered through the phase transposition operation.

\section{III.2. Decoupling transformation}

Decoupling (Clark's) transformation matrix is applied first. Let the correlation between original phase variables andnew $(\alpha, \beta)$ variables be given with $\underline{f}_{\alpha \beta}=\underline{C}_{\text {abcde }}$. 
Where $\underline{C}$ is the power-invariant transformation matrix [6]

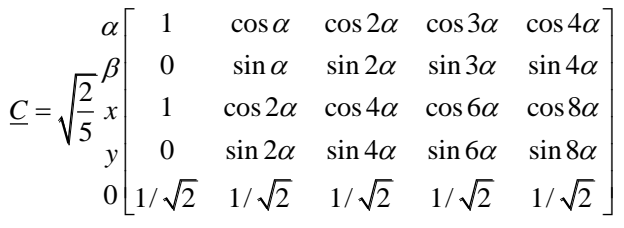

Application of (8) in conjunction with inverter voltages yields axis components of the inverter voltages

$$
\left[\begin{array}{l}
v_{\alpha}^{I N V} \\
v_{\beta}^{I N V} \\
v_{x}^{I N V} \\
v_{y}^{I N V} \\
v_{0}^{I N V}
\end{array}\right]=\underline{C}\left[\begin{array}{l}
v_{A} \\
v_{B} \\
v_{C} \\
v_{D} \\
v_{E}
\end{array}\right]
$$

Which can be further expressed, using correlation (1), as functions of the voltage axis components of the two machines

$$
\left[\begin{array}{c}
v_{\alpha}^{I N V} \\
v_{\beta}^{I N V} \\
v_{x}^{I N V} \\
v_{y}^{I N V} \\
v_{0}^{I N V}
\end{array}\right]=\underline{C}\left[\begin{array}{c}
v_{a s 1}+v_{a s 2} \\
v_{b s 1}+v_{c s 2} \\
v_{c s 1}+v_{e s 2} \\
v_{d s 1}+v_{b s 2} \\
v_{e s 1}+v_{d s 2}
\end{array}\right]=\left[\begin{array}{c}
v_{\alpha s 1}+v_{x s 2} \\
v_{\beta s 1}-v_{y s 2} \\
v_{x s 1}+v_{\alpha s 2} \\
v_{y s 1}+v_{\beta s 2} \\
0
\end{array}\right]
$$

Due to the absence of the neutral conductor inverter zero sequence voltage components must equal zero. The correlation between inverter voltage axis components and individual machine's voltage axis components implies series connection between appropriate $\alpha-\beta$ and $\mathrm{x}-\mathrm{y}$ circuits of the two machines. A corresponding correlation between inverter output currents and $\alpha-\beta$ and $\mathrm{x}-\mathrm{y}$ current components of the two machines is obtained by using (8) in conjunction with (2).

$$
\begin{aligned}
& i_{\alpha}^{I N V}=i_{\alpha s 1}=i_{x s 2} \\
& i_{\beta}^{I N V}=i_{\beta s 1}=-i_{y s 2} \\
& i_{x}^{I N V}=i_{x s 1}=i_{\alpha s 2} \\
& i_{y}^{I N V}=i_{y s 1}=i_{\beta s 2}
\end{aligned}
$$

The zero sequence component is omitted due to the star connection of the system without neutral conductor.

\section{III.3. Model in the Stationary Common Reference Frame}

Upon application of the decoupling transformation matrix (9) onto inverter and rotor voltage equations of (3). Rotational transformation matrix, leading to the $d-q$ system of equations, is applied in conjunction with rotor equations (angle $\theta$ is the instantaneous rotor position, which is different for the two machines:

$$
\underline{D}_{r}=\left[\begin{array}{ccccc}
\cos \theta & -\sin \theta & & & \\
\sin \theta & \cos \theta & & & \\
& & 1 & & \\
& & & 1 & \\
& & & & 1
\end{array}\right]
$$

Since the stator-to-rotor coupling appears in $\alpha-\beta$ equations only and torque production' is entirely governed by $\alpha-\beta$ current (flux) components, rotational transformation is not applied to $\mathrm{x}-\mathrm{y}$ rotor equations. As rotational transformation is applied to rotor windings only, indices $\alpha, \beta$ and $\mathrm{d}, \mathrm{q}$ are interchangeable in inverter (stator) equations (8)-(10).

The resulting system model is in the stationary common reference frame and is in general of the $15^{\text {th }}$ order. However, taking into account that rotor windings of the two machines are short-circuited, rotor $x-y$ component equations and rotor zero sequence equation can be omitted from further consideration. Zero sequence component equation for the inverter can be omitted as well. The electro-magnetic part of the drive system can then be represented with eight first-order differential equations. The four inverter equations are

$$
\begin{aligned}
& v_{d}^{I N V}=R_{s 1} i_{d}^{I N V}+\left(L_{l s 1}+L_{m 1}\right) \frac{d i_{d}^{I N V}}{d t}+L_{m 1} \frac{d i_{d r 1}}{d t}+R_{s 2} i_{d}^{I N V}+L_{l s 2} \frac{d i_{d}^{I N V}}{d t} \\
& v_{q}^{I N V}=R_{s 1} i_{q}^{I N V}+\left(L_{l s 1}+L_{m 1}\right) \frac{d i_{q}^{I N V}}{d t}+L_{m 1} \frac{d i_{q r 1}}{d t}+R_{s 2} i_{q}^{I N V}+L_{l s 2} \frac{d i_{q}^{I N V}}{d t} \\
& v_{x}^{I N V}=R_{s 1} i_{x}^{I N V}+L_{l s 1} \frac{d i_{x}^{I N V}}{d t}+R_{s 2} i_{x}^{I N V}+\left(L_{l s 2}+L_{m 2}\right) \frac{d i_{x}^{I N V}}{d t}+L_{m 2} \frac{d i_{d r 2}}{d t} \\
& v_{y}^{I N V}=R_{s 1} i_{y}^{I N V}+L_{l s 1} \frac{d i_{y}^{I N V}}{d t}+R_{s 2} i_{y}^{I N V}+\left(L_{l s 2}+L_{m 2}\right) \frac{d i_{y}^{I N V}}{d t}+L_{m 2} \frac{d i_{q r 2}}{d t}
\end{aligned}
$$

Or, in terms of individual machine $\mathrm{d}-\mathrm{q}$ axis stator voltage components (according to (9))

$$
\begin{aligned}
& v_{d}^{I N V}=v_{d s 1}+v_{x s 2} \\
& v_{q}^{I N V}=v_{q s 1}-v_{y s 2} \\
& v_{x}^{I N V}=v_{x s 1}+v_{d s 2} \\
& v_{y}^{I N V}=v_{y s 1}+v_{q s 2}
\end{aligned}
$$


Rotor voltage equilibrium equations of the two machines are:

$$
\begin{aligned}
& 0=R_{r 1} i_{d r 1}+L_{m 1} \frac{d i_{d}^{I N V}}{d t}+\left(L_{l r 1}+L_{m 1}\right) \frac{d i_{d r 1}}{d t}+\omega_{1}\left(L_{m 1} l_{q}^{I N V}+\left(L_{l r 1}+L_{m 1}\right) i_{q r 1}\right) \\
& 0=R_{r 1} i_{q r 1}+L_{m 1} \frac{d i_{q}^{I N V}}{d t}+\left(L_{l r 1}+L_{m 1}\right) \frac{d i_{q r 1}}{d t}-\omega_{1}\left(L_{m 1} l_{d}^{I N V}+\left(L_{l r 1}+L_{m 1}\right) i_{d r 1}\right) \\
& 0=R_{r 2} i_{d r 2}+L_{m 2} \frac{d i_{x}^{I N V}}{d t}+\left(L_{l r 2}+L_{m 2}\right) \frac{d i_{d r 2}}{d t}+\omega_{2}\left(L_{m 2} i_{y}^{I N V}+\left(L_{l r 2}+L_{m 2}\right) i_{q r 2}\right) \\
& 0=R_{r 2} i_{q r 2}+L_{m 2} \frac{d i_{y}^{I N V}}{d t}+\left(L_{l r 2}+L_{m 2}\right) \frac{d i_{q r 2}}{d t}-\omega_{2}\left(L_{m 2} i_{x}^{I N V}+\left(L_{l r 2}+L_{m 2}\right) i_{d r 2}\right)
\end{aligned}
$$

Finally, torque equations of the two series connected machines are given in terms of inverter current axis components with

$$
\begin{aligned}
C_{e m 1} & =P_{1} L_{m 1}\left[i_{d r 1} i_{q}^{I N V}-i_{d}^{I N V} i_{q r 1}\right] \\
C_{e m 2} & =P_{2} L_{m 2}\left[i_{d r 2} i_{y}^{I N V}-i_{x}^{I N V} i_{q r 2}\right]
\end{aligned}
$$

\section{Design of sliding mode control}

The sliding mode control is one of simplest approaches of the robust control. Very good performances (response time, precision) can be obtained in the presence of uncertainties on the parameters of the system and their variations on the one part, and uncertainties on the models of the system on the other part. These performances are obtained at the price of a very strong activity of order which can result in very strong oscillations called "Chattering". The design of the controllers by sliding mode takes into account the problems of stability and good performances in a systematic way in its approach, which is devised into three principal stages [6]:

-Choice of surfaces,

-Establishment of the conditions of existence and convergence,

-Determination of the law of control.

\section{IV.1. Choice of the surface of commutation}

J.J. Slotine proposes a format general equation to determine sliding surface

$$
s(x)=\left(\frac{d}{d t}+\lambda\right)^{n-1} e
$$

$e=X_{d}-X$ : Variation

$\lambda:$ Positif coefficient

$\mathrm{n}$ : order of the system

$X_{d}$ : Desired value

\section{IV.2. Condition of convergence}

The condition of convergence is defined by the equation of Lyapunov. It makes surface attractive and invariant

$$
s(x) \cdot \dot{s}(x)<0
$$

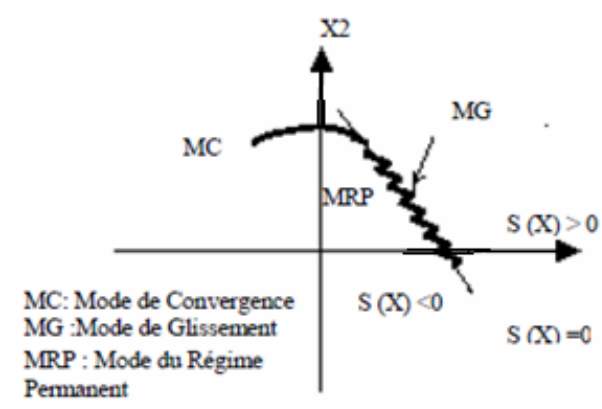

Figure 2. Modes of trajectory in the plan of phase.

\section{Sliding mode control of a Five-Phase Series-Connected Two-Motor Drive}

If one chooses $n=1$, surfaces are written: For the first machine:

$$
\left\{\begin{array}{l}
S\left(\Omega_{r 1}\right)=\Omega_{r 1 r e f}-\Omega_{r 1} \\
S\left(\phi_{r 1}\right)=\phi_{r 1 r e f}-\phi_{r 1} \\
S\left(i_{d 1}^{s}\right)=i_{d 1 r e f}^{s}-i_{d 1}^{s} \\
S\left(i_{q 1}^{s}\right)=i_{q 1 r e f}^{s}-i_{q 1}^{s}
\end{array}\right.
$$

For the second machine:

$$
\left\{\begin{array}{l}
S\left(\Omega_{r 2}\right)=\Omega_{r 2 r e f}-\Omega_{r 2} \\
S\left(\phi_{r 2}\right)=\phi_{r 2 r e f}-\phi_{r 2} \\
S\left(i_{d 2}^{s}\right)=i_{d 2 r e f}^{s}-i_{d 2}^{s} \\
S\left(i_{q 2}^{s}\right)=i_{q 2 r e f}^{s}-i_{q 2}^{s}
\end{array}\right.
$$

Decoupling resulting from the orientation of the rotor flow of the two machines enables us to control flow and speed separately, by using the current $i_{d}^{s}$ for the control of flow and the current $i_{q}^{s}$ for the speed control.

\section{V.1. Application of the control to the first machine}

Along the axe "d"

$$
\dot{S}\left(\phi_{r 1}\right)=0 \Rightarrow\left\{\begin{array}{l}
i_{d 1 n}^{s}=K_{\phi 1} \operatorname{sign}\left(S\left(\phi_{r 1}\right)\right) \\
i_{d 1 e q}^{s}=\frac{T_{r 1}}{L_{m 1}} \phi_{r 1 r e f}+\frac{1}{L_{m 1}} \phi_{r 1}
\end{array}\right.
$$


And

$$
\begin{gathered}
\dot{S}\left(i_{d 1}^{s}\right)=0 \Rightarrow \\
\left\{\begin{array}{l}
V_{d 1 n}^{s}=K_{i d 1} \operatorname{sign}\left(S\left(i_{d 1}^{s}\right)\right) \\
V_{d l e q}^{s}=\left(\sigma_{1} L_{s 1}+L_{l s 2}\right) i_{d 1 r e f}^{s}+R_{1} l_{d 1}^{s}-\left(\sigma_{1} L_{s 1}+L_{l s 2}\right) \omega_{s 1} i_{q 1}^{s}-\frac{L_{m 1}}{T_{r 1} L_{r 1}} \phi_{1}^{r}
\end{array}\right.
\end{gathered}
$$

Along axe "q"

$$
\dot{S}\left(\Omega_{r 1}\right)=0 \Rightarrow\left\{\begin{array}{l}
i_{q 1 n}^{s}=K_{\Omega 1} \operatorname{sign}\left(S\left(\Omega_{r 1}\right)\right) \\
i_{q 1 e q}^{s}=\frac{J_{1} \dot{\Omega}_{r 1 r e f}+f_{1} \Omega_{r 1}}{p_{1} \frac{L_{m 1}}{L_{r 1}} \phi_{r 1}}
\end{array}\right.
$$

And

$$
\begin{aligned}
& \dot{S}\left(i_{q 1}^{s}\right)=0 \\
& \Rightarrow\left\{\begin{array}{l}
V_{q 1 n}^{s}=k_{i q 1} \operatorname{sign}\left(S\left(i_{q 1}^{s}\right)\right) \\
V_{q l e q}^{s}=\left(\sigma_{1} L_{s 1}+L_{l s 2}\right) i_{q 1 r e f}^{s}+R_{1} i_{q 1}^{s}+\left(\sigma_{1} L_{s 1}+L_{l s 2}\right) \omega_{s 1} i_{d 1}^{s}+\frac{L_{m 1}}{L_{r 1}} \omega_{r 1} \phi_{1}^{r}
\end{array}\right.
\end{aligned}
$$

\section{V.2.Application of the control to the second machine}

Along the axe "d"

$$
\left\{\begin{array}{l}
i_{d 2 n}^{s}=K_{\phi 2} \operatorname{sign}\left(S\left(\phi_{r 2}\right)\right) \\
i_{d 2 e q}^{s}=\frac{T_{r 2}}{L_{m 2}} \phi_{r 2 r e f}+\frac{1}{L_{m 2}} \phi_{r 2}
\end{array}\right.
$$

And

$$
\left\{\begin{array}{l}
V_{d 2 n}^{s}=K_{i d 2} \operatorname{sign}\left(S\left(i_{d 2}^{s}\right)\right) \\
V_{d 2 e q}^{s}=\left(\sigma_{2} L_{s 2}+L_{l s 1}\right) i_{d 2 r e f}^{s}+R_{2} i_{d 2}^{s}-\left(\sigma_{2} L_{s 2}+L_{l s 1}\right) \omega_{s 2} i_{q 2}^{s}-\frac{L_{m 2}}{T_{r 2} L_{r 2}} \phi_{2}^{r}
\end{array}\right.
$$

Along the axe "q"

$$
\left\{\begin{array}{l}
i_{q 2 n}^{s}=K_{\Omega 2} \operatorname{sign}\left(S\left(\Omega_{r 2}\right)\right) \\
i_{q 2 e q}^{s}=\frac{J_{2} \Omega_{r 2 r e f}+f_{2} \Omega_{r 2}}{p_{2} \frac{L_{m 2}}{L_{r 2}} \phi_{r 2}}
\end{array}\right.
$$

And

$$
\left\{\begin{array}{l}
V_{q 2 n}^{s}=K_{\Omega 2} \operatorname{sign}\left(S\left(i_{q 2}^{s}\right)\right) \\
V_{q 2 e q}^{s}=\left(\sigma_{2} L_{s 2}+L_{l s 1}\right) i_{q 2 r e f}^{s}+R_{2} i_{q 2}^{s}+\left(\sigma_{2} L_{s 2}+L_{l s 1}\right) \omega_{s 2} i_{d 2}^{s}+\frac{L_{m 2}}{L_{r 2}} \omega_{r 2} \phi_{2}^{r}
\end{array}\right.
$$

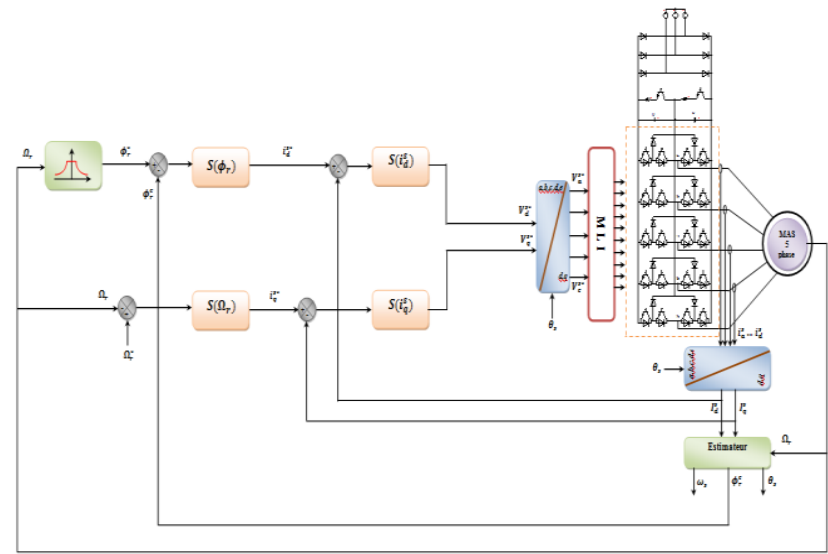

Figure 3. Sliding mode control of a Five-Phase SeriesConnected Two-Motor Drive

\section{Simulation results}

The transposition of the phases allowed the independent control from two machines. We notice that the speed and rotorique flow of two machines after a short transitory regime towards the compulosry references .During the application of the load at the moment $\mathrm{t}=0.5 \mathrm{~s}$, the speed decreases, then returns to its reference. We notice the same thing when the load is iliminated. The undulations of the couple are always due to the not sinusoidal shape of the tension of exit of the inverter.
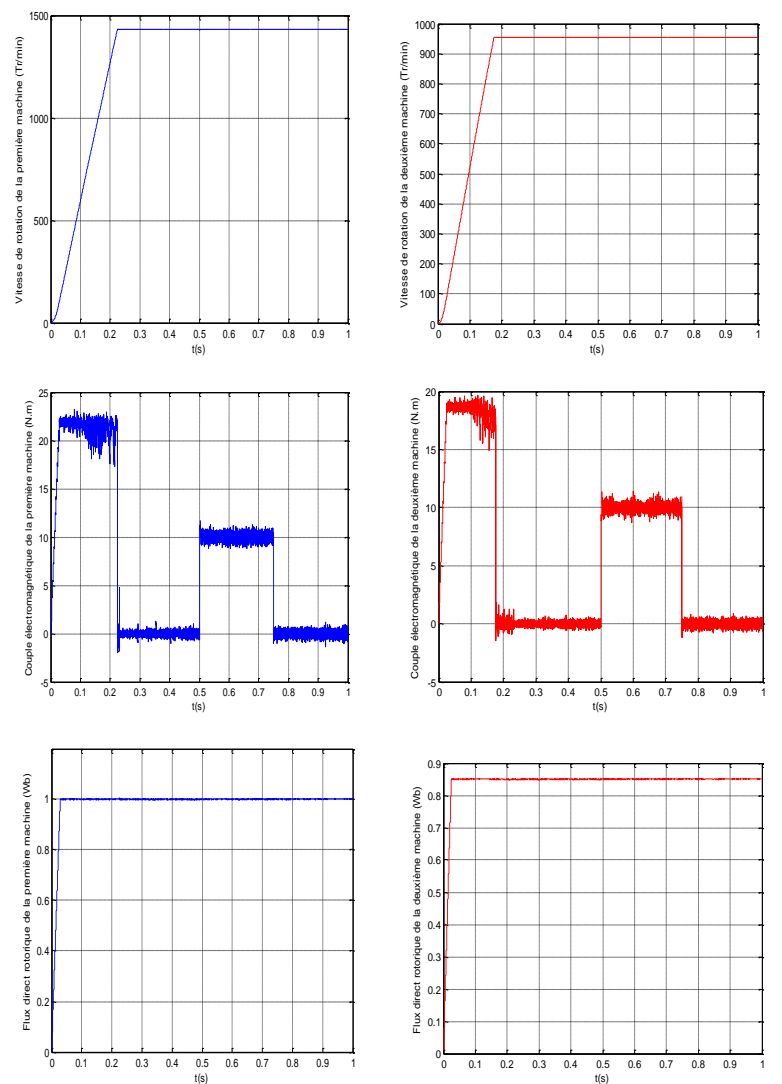

Figure 4. Simulation results of the Sliding mode control of a Five-Phase Series-

Connected Two-Motor Drive 


\section{Conclusion}

The results of simulation showed the importance of the transposition of phases applied for the independent control from two machines. We noticed that the use of regulators "sliding mode" improved the ansewer of the machine, beter than during the use of regulators PI, we supposed that the parameters do not vary, what is not the case in practice, the parameters of machines vary either by heating or by saturation, and thes variations influence directly the variables of exit of the control.

\section{Acknowledgements}

I would like to thank my advisor Lazhari Nezli for her constant support, suggestions and scientific guidance during all stages of my work.

\section{REFERENCES}

[1] E.Semail, E.Levi, A.Bouscayrol, X.Kestelyn, (2002) "Multi-machine modeling of two series connected five-phase synchronous machines: affect of harmonics on control", IEEE-IAS'04, Seattle (Washington), Vol.1, pp71-78.

[2] H.A.Toliyat, H.Xu, L.J.Petersen, (2002) "Five-phase induction motor drives with DSP-based control system ”, IEEE Transactions on Power Electronics, Vol.17, No. 4, pp524-533.

[3] E.Levi, M.Jones, S.N.Vukosavic, H.A.Toliyat "A novel concept of a multiphase, multi-motor vector controlled drive system supplied from a single voltage source inverter", IEEE [Lip-80].

[4] C.Namuduri and P.C. Sen, (1986) "A servo control system using a self controlled synchronous motor (SCSM) with sliding mode controller",IEEE IAS Annuel Meeting, pp56-65.

[5] E.Levi, M.Jones, S.N.Vukosavic, H.A.Toliyat, A.Iqbal, (2006) "Modelling, control and experimental investigation of a five-phase series-connected twomotor drive with single inverter supply", IEEE Trans, Energy Convers.

[6] T.A.Lipo, (2004) "A d-q model for six phase induction machines",proc. ICEM'80, pp.860-867, Athens, Greece, 1980 Trans,Power Electronics, Vol. 19, pp320-335. 